\title{
Reasons for Quitting, Reasons for Relapse, and Knowledge toward the Danger of Smoking in Active Smokers
}

\author{
Burhannudin Ichsan, Yudwari Adhicha Nuredis, Wildan Priscillah \\ Department of Medical Community/ Public Health, Faculty of Medicine, \\ Universitas Muhammadiyah Surakarta
}

\section{ABSTRACT}

Background: Smoking is a national and world problem. The prevalence of smoking in Indonesia is quite high. Not all smokers have the motivation to quit smoking. Most people who quit smoking have relapse experiences. There have been many advertisements about the dangers of smoking. The dangers of smoking on average are known by everyone, including smokers themselves.

Subjects and Method: This study is a quailtative study which intends to determine the reasons for quitting and relapse and their knowledge of the dangers of smoking. The research subjects consisted of 29 people who met the criteria, namely smokers who had quit and then relapsed again in the city of Surakarta. Results: The results showed that the reasons for the respondents to quit smoking were: sickness, not allowed by their parents, no money, a work environment that did not allow them for smoking, having children, reflexes or suddenly wanting to not smoke, wanting to live healthy, because they wanted to register for official school, and because they like sports. Reasons for respondents who had stopped smoking relapsed, namely: recovery from illness, factors from friends and the environment, due to accidentally or suddenly smoking, addiction or dependence, and because of stress. The knowledge of respondents who relapsed from smoking cessation behavior about the dangers of smoking, namely: smoking is a danger, cigarettes can cause cancer, smoking is detrimental to health, smoking can cause lung disease, coughing, shortness of breath, heart, smoking can cause throat disease, smoking can cause stroke, don't know the dangers of smoking, and some say it all depends on God.

Conclusion: This study shows that people who return to smoking have a good knowledge of the dangers of smoking. The results of this study indicate that there are factors other than knowledge that influence smoking behavior.

Keywords: smoker, quit, relapse, knowledge

\section{Correspondence:}

Burhannudin Ichsan. Department of Medical Community/ Public Health, Faculty of Medicine, Universitas Muhammadiyah Surakarta. Komplek Kampus 4 UMS Gonilan Kartasura, Jl. A. Yani Tromol Pos 1 Pabelan Kartasura, Sukoharjo, Surakarta, Central Java, Indonesia. Email: bi268@ums.ac.id. Mobile: o81325495988.

Cite this as:

Ichsan B, Nuredis YA, Priscillah W (2021). Reasons for Quitting, Reasons for Relapse, and Knowledge toward the Danger of Smoking in Active Smokers. J Health Promote Behav. 05(04): 232-239. https://doi.org/10.26911/thejhpb.2020.05.04.01.

(i) (9) Journal of Health Promotion and Behavioris licensed under a Creative Commons Attribution-NonCommercial-ShareAlike 4.o International License.

\section{BACKGROUND}

Smoking is a risk factor for several noncommunicable diseases such as chronic obstructive pulmonary disease (COPD), atherosclerosis, stroke, and some malignancies (Raghu et al., 2015). The popularity of smoking continues and this is contrary to rational explanations. Most smokers admit that what they are doing is dangerous and many report that they do not enjoy it, but they continue to smoke (West, 2017). 
Smoking is a world public health threat, which is known to be able to kill more people than HIV / AIDS, tuberculosis and malaria (Tezera \& Endalamaw, 2019). Smoking is common in the world, and this is especially the case among youth and in developing countries (Pan et al., 2019).

Smoking causes the death of an estimated 7.2 million people each year. Smoking is still the leading cause of premature death. About a quarter of adults worldwide are smokers, and smoking is also widespread among adolescents. Therefore, smoking is a priority for public health concerns (Zeiher, Starker, and Kuntz, 2018).

There are attempts by smokers to recover from their behavior. Some of the people who try to recover from their behavior fail. This study aims to determine the reasons smokers fail in their efforts to recover from their smoking behavior.

\section{SUBJECTS AND METHOD}

\section{Study Design}

This study is a qualitative phenomenological study that aims to determine the reasons for smokers to quit and relapse and their knowledge of the dangers of smoking.

\section{Population and informant}

The number of study subjects is twenty nine people in the city of Surakarta. The criteria for the subject were smokers who had quit but then relapsed who were domiciled in Surakarta. The sampling technique is purposive sampling.

\section{Study Instrument}

The study instrument is the researchers themselves. Researchers tried to obtain data by interviewing informants. Data collection was carried out by in-depth interviews.

\section{DataAnalysis}

Interview data were recorded and then made a verbatim transcript. Data analysis was performed using thematic analysis.

\section{RESULTS}

This study found several reasons to quit smoking. These reasons are: illness, parents not allowed, do not have money, a work environment that does not allow smoking, having small children, reflexes or suddenly want to not smoke, want to live healthy, because you want to register for official school, and because you like Sports.

The reasons for relapse from quitting smoking are several. These reasons are: recovering from illness, factors from friends and the environment, because smoking accidentally or suddenly, addiction or dependence, and because of stress.

The knowledge of the average smoker is the same, namely that cigarettes are dangerous. The knowledge of respondents who relapsed from smoking cessation behavior about the dangers of smoking, namely: smoking is a danger, cigarettes can cause cancer, smoking is detrimental to health, smoking can cause lung disease, coughing, shortness of breath, heart, smoking can cause throat disease, smoking can cause stroke Don't know the dangers of smoking, and some say it all depends on the above.

\section{A.1. The reason smokers try to get rid of smoking behavior.}

\section{A.1.1. The reason for quitting smoking is because of illness}

The reason for stopping smoking in some smokers is because of illness. Sickness suffered by smokers that causes smoking cessation are: 1) cough, 2) tuberculosis, 3) typhus, 4) asthma, 5) shortness of breath, 6) chest pain, 7) stomach acid, 8) chills, 9) fever or flu , and 10) lung disease.

Some examples of respondents' statements are as follows:

"The reason I stopped first was because I was sick when I coughed" (Tn H, 31 years).

"The reason I stopped was because I was short of breath, I had difficulty 
breathing, and finally I wanted to stop, because I felt a little sick. So then the lungs are tight, keep coughing "( $\operatorname{Tn} \mathrm{A})$.

"At that time I had a cough, and I felt that smoking was not good, then I quit" (Mr $\mathrm{Y}, 38$ years).

Some of them did not mention the type of illness. Examples are as follows.

"I keep smoking, bro, at least 1 week to stop because of illness" (Mr S, 27 years).

Some mentioned diseases not related to the respiratory tract. For example, the problem is as follows.

"Because back then we were all sick, had a fever or flu and it kept getting better for 2-3 days then it seemed like we wanted to try to stop ..." (Mr HP, 51 years).

A.1.2. The reason for quitting smoking is because parents don't allow it

Part of the reason for quitting smoking is because parents don't allow it. An example of the statement is as follows.

"Parents also don't allow it" (SA).

A.1.3. The reason for quitting smoking is because you don't have money

Part of the reason for quitting smoking is because you don't have money. Some examples of respondents' statements are as follows.

"Because there is no money, mas" ( $\mathrm{Mr}$ A, 33 years).

"At that time there was no money, mas" (Mr A, 30 years old).

A.1.4. The reason for quitting smoking is due to work environment factors that do not allow smoking

Part of the reason for quitting smoking is because the work environment does not allow smoking. Some examples of respondents' statements are as follows.

"Yes, it stopped because of the environment, mas. It was because the work environment at that time didn't smoke, mas. I used to work in the garment, only a few people smoked. Then I stopped smoking too"(Bro, 17 years).

"Yes, actually I never smoked, so try and try it, until high school in grade 2 I quit, working was an environment where I couldn't smoke, because of the AC environment" (Tn A).

A.1.5. The reason for quitting smoking is because they have young children

Most of the reason for quitting smoking is because of having young children. Examples of respondents' statements are as follows.

"Because my child is young, I have to reduce or stop smoking. Initially the intention was to reduce it but instead it stopped for a month" (Tn W).

A.1.6. The reason for quitting smoking is because of reflex or sudden desire not to smoke

Several reasons to quit smoking are because of the reflex to not smoke. Examples of respondents' statements are as follows.

"Yes, it's just a reflex, so I don't want to smoke" (Mr S, 54 years).

Another example of a statement is as follows.

"There is no intention whatsoever, just want to stop like that, don't have any motivation ( $\mathrm{Mr} \mathrm{B}$ ).

A.1.7. The reason for quitting smoking is because they want to live a healthy life

Part of the reason for quitting smoking is because they want to live a healthy life. Examples of respondents' statements are as follows.

"At that time I wanted to live a healthy life, bro, but after being exposed to stress again, I came back again" (Mr JS).

Another example of a statement is as follows. 
"Yes, I want to stop. Yes, he said he was not healthy or something "(Mr A).

A.1.8. The reason for quitting smoking is because you want to register for official school

Part of the reason for quitting smoking is because you want to register for official school. Examples of respondents' statements are as follows.

"At that time I wanted to register for official school, so I tried to quit because it made me physically stronger" (MZA).

A.1.9. The reason for quitting smoking is because you like sports

Part of the reason for quitting smoking is because you like sports. Examples of respondents' statements are as follows.

"I also like sports, so it's not good if I don't have enough breath" (SA).

A.2. The reasons / factors of smokers fail in trying to recover from their behavior.

\section{A.2.1. Return to smoking after recovering from illness}

The reason for returning to smoking to smokers is partly because the illness that caused him to stop smoking has healed. Some examples of respondents' statements are as follows:

"Keep smoking again after?" (Bro Y, 24 years). "After recovering, Mas (Mr R).

Another example of a statement is as follows.

"After that, I started smoking again after the illness healed" (Mr Y, 24 years). "Yes" (Mr Y).

\section{A.2.2. Return to smoking because of the factors of friends and environment}

The reason for returning to smoking as part of smokers is because of friends and the environment.

Some examples of respondents' statements are as follows:
"I started to fail at first from the environment as well as my friends smoking, so finally I started again" (SA).

Another example of a statement is as follows.

"..But it turns out that after 1 month I got together with my friends to try again, so how come I can feel it again finally it continues again" (Mr. HP, 51 years).

\section{A.2.3. Going back to smoking by accident}

The reason some smokers return to smoking is that they accidentally smoke again.

Examples of respondents' statements are as follows:

"At first it wasn't on purpose, because accidentally it was like a normal day we smoke, you know. Immediately take a cigarette and then suddenly realize that you can stop smoking for 8 days, why don't you continue? But if it's already already, then you can continue "( $\mathrm{Mr} \mathrm{M})$.

\section{A.2.4. Returning to smoking because there is an addiction or addiction}

The reason for returning to smoking as part of smokers is because there is a kind of addiction or desire to return to smoking.

Examples of respondents' statements are as follows:

"Well if I don't smoke I feel tired, so I smoke again" (Mr M, 52 years).

Examples of other respondents' statements are as follows.

"So after eating, I usually bring candy, but I don't bring it and I want to try smoking a cigarette. Finally starting to get addicted again. " (Mr. FA).

Examples of other respondents' statements are as follows.

"I don't know, like there is a sense of addiction." (Brother $\mathrm{A}$ ).

Examples of other respondents' statements are as follows. 
Ichsan et al./ Reasons for Quitting, Relapse, and Knowledge toward the Danger of Smoking

"I can't get away from cigarette mas so I smoke again." (Mr A, 33 years).

\section{A.2.5. Going back to smoking because of stress}

The reason some smokers return to smoking is because of stress.

Examples of respondents' statements are as follows:

"At that time I wanted to live a healthy life, bro, but after being exposed to stress again, I came back again" (Mr J).

Examples of other respondents' statements are as follows.

"What do you do, bro, because there are a lot of thoughts, bro. It's better just to get new inspiration like that hehehe "(Bro W).

A.3. Knowledge of the dangers of smoking from people who fail to quit smoking

\section{A.3.1. Cigarettes are a danger}

Some respondents said in general that smoking is a danger. An example of the statement is as follows.

"You know the danger, right? It means there are advertisements "(interviewer). "Yes, you know, but if you are addicted, what can I do?" (Bro B).

Another example of a statement is as follows.

"Yes, if it's dangerous, it's like in the news, right? Yes, the danger is like that, but to my knowledge it depends on the person, right now, nowadays many people don't smoke but have diseases, while those who smoke are healthy "(Bro A,). "

\section{A.3.2. Cigarettes can cause cancer}

Some respondents said that smoking can cause cancer. An example of the statement is as follows.

"Then apart from that, what is the danger, do you know? (Bro Y, 24 years). "Yes, that's cancer, bro". (Bro I, 26 years old).
Another example of a statement is as follows.

"Yes, bro, it can cause cancer, bro" (Bro R,)."

\section{A.3.3. Cigarettes are detrimental to health}

Some respondents said that smoking can be detrimental to health. An example of the statement is as follows.

"... And the only negative thing is it damages the body or health? (Bro MZA).

Another example of a statement is as follows.

"... if the loss is in terms of health" (Mr L, 45 years).

\section{A.3.4. Cigarettes can cause lung, cough, breath and heart disease}

Some respondents said that smoking can cause lung disease. An example of the statement is as follows.

"The loss is the lungs ..." (Mr S, 54 years).

Another example of a statement is as follows.

"The lungs also can't breathe out if you sleep like shortness of breath" (Mr A).

Some of the respondents said that smoking causes coughing. An example of the statement is as follows.

"In terms of health, it automatically becomes a cough, the average smoker coughs every night" (Mr B).

Some respondents stated that smoking can interfere with lung and heart health. An example of the statement is as follows.

"There is no benefit, yes, but the disadvantage is from lung and heart health, yes" (Mr H, 31 years).

Some respondents said that smoking is not good for breathing. An example of the statement is as follows.

"Eemm, from the first few years I was not healthy, it makes it hard for my body to breathe and not hurry, bro" (JS). 
Some respondents said that smoking can cause mouth disease. An example of the statement is as follows.

"Yes, in our mouths there are diseases like that, bro" (Brother A, 30 years old).

\section{A.3.5. Cigarettes can cause sore throat}

Some respondents said that smoking can cause throat disease. An example of the statement is as follows.

"Continues to damage the throat" (Mr Y).

Another example of a statement is as follows.

"... if you lose a lot, like a sore throat ..." (Mr S, 51 years old).

\section{A.3.6. Respondents do not know the} disadvantages of smoking

Some respondents said they did not know the disadvantages of smoking. An example of the statement was as follows.

"Do you know the advantages and disadvantages of cigarettes, sir? (Interviewer). "I don't know, if you don't smoke, you're tired, keep on smoking" (Mr M, 52 years).

\section{A.3.7. Smoking may cause a stroke \\ Some respondents said that smoking might cause a stroke. An example of the statement is as follows. \\ "... maybe we also know a stroke" (Mr HP, 51 years).}

\section{A.3.8. Depends on the above}

Some respondents said that it all depends on the above. An example of the statement is as follows.

"If smoking is bad, if all the diseases come from above, bro, if I myself don't think about smoking causing pain and so on. I also don't really think about it, if I am about age, it is the question of age that regulates the above, if you are old, you will stop, bro "( $\mathrm{Y}, 38$ years).

Another example of a statement is as follows.
"If there are too many dangers. It's already written that smoking kills you like that, hehe, but that's how it depends on the Almighty, just physically. Many do not smoke, their lifespan is not that long, many of them smoke, but they have a long life span.

\section{DISCUSSION}

This study found that smokers who had quit smoking had several reasons. The reasons for quitting smoking are: 1) sickness, 2) not allowed by parents, 3) not having money, 4) a work environment that does not allow smoking, 5) having small children, 6) reflex or suddenly want not to smoke, 7) want to live healthy, 8) want to register for official school, 9) because they like sports.

The reasons for relapse from smoking cessation attempts are several. These reasons are: 1) recovering from illness, 2) factors from friends and environment, 3) because smoking accidentally or suddenly, 4) addiction or dependence, and 5) because of stress.

This study also found interesting findings regarding the knowledge of those who failed to recover from smoking. Their knowledge about smoking, namely: 1) smoking is a danger, 2) smoking can cause cancer, 3) smoking is detrimental to health, 4) smoking can cause lung disease, coughing, shortness of breath, and heart, 5) smoking can cause throat disease, 6 ) smoking can cause stroke, 7) not knowing the dangers of smoking, and 8) all depending on the God.

In general, this study shows that most respondents know that smoking is dangerous. There are other reasons as motivation to quit smoking. The reasons for quitting smoking in these respondents proved to be insufficient because they eventually relapsed again. Their knowledge regarding 
the dangers of smoking is actually quite complete, but it seems that they are not too sure that the diseases they mention really threaten them. Other studies related to this finding are as follows.

Georgiadou et al (2015) found that quitting smoking is a difficult process. The factors that influence it are: 1) level of education, 2) job satisfaction, and 3) presence of a partner.

Tsoh et al (2011) examined the role of individuals and families in order to quit smoking. This study found that to quit smoking, the intervention must involve the individual and his family.

Mohammad \& Alqassem (2013) examined the risk factors for failure to quit smoking among Saudi men in the city of Abha. They found that most people who quit smoking had relapse experiences. The reasons for relapse are: social influence of smoker friends, influence of daily stress, due to excessive smoking withdrawal symptoms, experience of side effects of a treatment, and being addicted to drugs. They also found that the development of symptoms and complications due to the effects of smoking did not reduce the rate of relapse in people who had quit smoking.

Buczkowski et al (2014) conducted qualitative research related to motivation to quit smoking, reasons for relapse, and models of how to quit. They found that two important motivations for quitting smoking were smoking bans at home and at work due to requests or regulations from other parties. The most frequent model of quitting is quitting spontaneously due to a triggering of a factor. The most frequent relapses are due to: stress, reduced enjoyment previously gained while smoking, and due to environmental influences.

The conclusion of this study is that the reasons for the respondents to stop smoking are: illness, parents are not allowed to, have no money, a work environment that does not allow smoking, have small children, reflexes or suddenly want not to smoke, want to live healthy, because they want to register official schools, and arenas like sports. Reasons for respondents who had stopped smoking relapsed, namely: recovery from illness, factors from friends and the environment, due to accidentally or suddenly smoking, addiction or dependence, and because of stress. The knowledge of respondents who relapsed from smoking cessation behavior about the dangers of smoking, namely: smoking is a danger, cigarettes can cause cancer, smoking is detrimental to health, smoking can cause lung disease, coughing, shortness of breath, heart, smoking can cause throat disease, smoking can cause stroke, Don't know the dangers of smoking, and some say it all depends on the God.

\section{AUTHOR CONTRIBUTION}

BI: designing, making verbatim transcripts and analyzing

YAN \& WP: go into the field and interview informants.

\section{CONFLICT OF INTEREST}

There is no conflict of interest in this study.

FUNDING AND SPONSORSHIP

This study is funded by Universitas Muhammadiyah Surakarta

\section{ACKNOWLEDGEMENT}

Researchers would like to thank all informants who were willing to be involved in this study.

\section{REFERENCE}

Buczkowski K, Marcinowicz L, Czachowski S, Piszczek E (2014). Motivations toward smoking cessation, reasons for relapse, and modes of quitting: results 
Ichsan et al./ Reasons for Quitting, Relapse, and Knowledge toward the Danger of Smoking

from a former and qualitative study among former and current smokers. Patient Prefer Adherence. 8: 13531363. https://doi.org/10.2147/ppa.s67767.

Georgiadou C, Lavdaniti M, Psychogiou M, Tzenalis A, Sgantzos M, Krepia DS (2015). Factors affecting the decision to quit smoking of the participants of a hospital based smoking cessation program in Greece. Journal of caring sciences. 4(1): 1-11. doi: 10.5681/jcs.2015.001.

Mohammad YM, Alqassem (2013). Risk factors for failure to quit cigarette smoking among male Saudi's in Abha city. Merit research Journal of Medicine and medical sciences. 1(2): 018027. https://www.meritresearchjournals.org/mms/content/2013/Septem ber/Alqassem.pdf.

Pan B, Jin X, Jun L, Qiu S, Zheng Q, Pan M (2019). The relationship between smoking and stroke: a meta-analysis. Medicine (Baltimore). 98(12):e14872. https://doi.org/10.1097/md.000000 0000014872.

Raghu S, Rao MV, Pulivartthi SK, Srikanth JK (2015). Awareness of harmfull effect of smoking among smokers. J of Evolution of Med and Dent Sci. 4(80):
13937-13942. DOI: 10.1426o/jemds/2015/1985.

Tezera N, Endalamaw A (2019). Current cigarette smoking and its predictors among school-going adolescents in East Africa: A systematic review and meta-analysis. International Journal of Pediatrics. https://doi.org/10.1155/2019/4769820.

Tsoh JY, Tong EK, Gildengorin G, Nguyen TT, Modayil MV, Wong C, McPhee SJ (2011). Individual and family factors with intention to quit among male Vietnamese American smokers: implication for intervention development. Addictive Behaviors. 36(2011)294301. Doi: 10.1016/j.addbeh.2010.11.009.

West R (2017). Tobacco smoking: health impact, prevalence, correlates and interventions. Psychology \& Health. 32(8): 1018-1036, https://doi.org/10$.1080 / 08870446.2017 .1325890$.

Zeiher J, Starker A, Kuntz B (2018). Smoking behaviour among children and adolescents in Germany, results of the cross-sectional KiGGS wave 2 study and trends. Journal of Health Monitoring. 3(1). DOI: $0.17886 / \mathrm{RKI}-$ GBE-2018-025. 